\title{
The Development of Tree Form
}

\author{
Brayton F. Wilson \\ Department of Foresty and Wildlife Management, University of Massachusetts, Amherst, MA 01003
}

Form is the sum of those features of the crown, major branches, and stem that characterize a whole tree. The various characters used to describe form depend on the use of the description. Landscape architects may classify form on the basis of geometric crown shapes and leaf densities because they are interested in how the tree will fill space. Ecologists often classify form on the basis of how it affects leaf display and energy exchange for photosynthesis and transpiration (3). Hallé et al. (5) classified tree form on the basis of "architectural" developmental models.

The problem faced in studying the development of form is to explain how a mature tree, an organized, recognizable structure with thousands, or hundreds-of-thousands, of leaves and twigs grew from the single shoot of a germinating seed. There are two aspects of the answer of this problem that should be handled in sequence: a) to describe what actually happens during the process of form development, and b) to describe how that process is controlled.

\section{PROCESSES IN FORM DEVELOPMENT}

The most critical step in the understanding of form development in trees was stated by H.M. Ward (12): "what a complex matter in its summation, but what a simple one in its graduated steps, the shaping of a tree is. " In modern model-oriented terms, form development is an iterative process. Film makers use the regularity of this iterative process to develop computer graphics that "grow" realistic trees of various species (11). If the term "axis" is defined to include any branch, branchlet, or stem produced by a single apical meristem, then trees grow by each axis elongating and by each axis branching to add new lateral axes.

Hallé et al. (5) state that the single most important functional character in the classification of their developmental models is whether or not the terminal meristem of an axis persists, because in many species it does not. An axis may not branch, particularly if it is growing relatively slowly, and the branches may grow out while 
the leaves are still present or they may be delayed until later, often until after a winter dormant period in many temperate species. Thus, the process of elongation and branching is repeated again and again. When rates exceed zero, each axis elongates and produces new axes to build up the huge population of axes that constitute the tree.

Axes are added in patterns, with relative lengths in positions consistent for each species. For example, the iterative process is annual in temperate trees (15). Lateral branches grow out after a season of cold treatment. The number of laterals is a function of axis length and the shortest axes produce no laterals. If the terminal meristem does not persist, as in Populus, Betula, etc., the most distal lateral grows in the same direction as the parent axis, effectively replacing it. Among branches produced on an axis in a year, the distal laterals are usually the longest, although generally shorter than the parent or the replacement so that elongation decreases as the generations, or order number, of axes increases. Ultimately, as order number increases, elongation is so slow that axes do not branch 'and a maximum order number is reached.

In addition to the iterative processes of elongation and branching in specific patterns, axes grow in characteristic orientations. The tremendous range of orientations among species and within a tree can be best appreciated in tropical trees (5). Laterals usually grow at angles to their parent axes, but they may bend or twist to grow vertically or in two-ranked, bilaterally symmetrical, branching structures.

Once the characteristic framework of axes is established by elongation, branching and axis' orientation, then secondary processes affect form. (i) Axes thicken differentially with the thicker forming major branches and the thickest the stem (4). (ii) Axes die, particularly the smallest and those shaded by- other branches, resulting characteristically in a tree with a stem bare of lower branches and the major branches bare of laterals toward the base. (iii) Axes may change orientation either through rotation of a parent axis, sagging from weight or being bent by internal reaction wood (17).

Thus the processes in form development are: Elongation and branching in specific patterns and orientations, differential thickening and mortality, and secondary changes in orientation. These processes proceed iteratively, in the many connected axes of the system we call a tree.

Like many systems, trees are somewhat stable and tend to return to their original condition after perturbation. Perturbation for trees means injury to leaves or, more importantly for the development of form, the destruction of the terminal meristem of axes. Destruction of terminal meristems by insects, disease, abrasion, weather, flower formation, or cultural practices is common in trees. There are two major possible responses following injury to a terminal meristem. Previously inhibited buds may grow out rapidly and often vertically. When they form in older trees, Hallé et al. (5) call the growth of these new shoots "reiteration", because it follows the pattern of a young, vigorous tree. Another possible response is that existing laterals near the injury may bend upward, through formation and action of reaction wood and replace the injured axis. If more than one lateral replaces the injured axis then there is a fork. This forking following injury or flowering is common in the stems of trees, particularly when they pass from the juvenile to the mature phase. Injuries have a constant modifying effect on development of some axes, but in general the response is to restore the characteristic form of the tree rather than to change it.

\section{CONTROL OF THE DEVELOPMENT OF FORM}

There are three major mechanisms that control the development of freeform: (i) correlative processes, called apical dominance and control, among axes that determine both the patterns and the orientation of axis development; (ii) shading that reduces light intensity and branch productivity, ultimately leading to death of axes; and (iii) allocation mechanisms that maintain feedbacks between leaf and wood production for both transport capacity and mechanical support.

\section{Apical dominance and control}

Apical dominance refers to whether lateral buds grow out and apical control refers to the relative length and orientation of the lateral axes that do grow out. Researchers who study herbaceous plants use only the term apical dominance. Many of those who study trees find that the term apical control is useful, particularly in describing regulation of growth in large branches (2).

To test whether a process is under either apical dominance or apical control, remove the terminal (i.e., simulate injury) and see whether the process changes. Major possible results of removing the terminal axis are: (i) old, inconspicuous lateral buds grow out to form epicormic shoots, therefore bud growth was inhibited by the terminal; (ii) the most distal lateral, or several laterals, bend to replace the injured terminal (this may occur either in elongating laterals or in thick, large branches), therefore the terminal regulates the orientation of the laterals; or (iii) the most distal laterals elongate more than they would have if the terminal had remained intact, therefore the terminal inhibits lateral elongation.

The physiological bases for apical dominance and control are complex and not well understood $(15,18,20)$. They have been investigated primarily in herbaceous plants with respect to lateral bud inhibition. Auxin seems to be intimately involved in dominance and control in trees because, if it is put on the cut surface of an injured terminal in a replacement experiment, the buds stay inhibited, lateral elongation does not increase, and the laterals do not bend either through differential elongation or reaction wood formation. What auxin is doing to this range of processes in replacement experiments is not known. The process is complex and the other major classes of hormones undoubtedly are involved with auxin (1). It is difficult to reconcile basipetal polar transport of auxin, which fits with control of pattern formation, with inhibition of elongation of branches because the auxin would apparently have to move acropetally to reach the elongation tip of the branch.

An interesting aspect of apical control is reaction wood formation in branches. If branches on an intact tree are experimentally restrained out of their normal position, by bending them up, down, or sideways, they form reaction wood that is located seas to bend the branch back to its original position (10). There is a lengthy debate in the literature as to whether the stimulus to form reaction wood in these experiments is mechanical from bending, or a result of changing angle relative to gravitational force (17). Whatever the stimulus, branches do seem to have a "preferred position" that is maintained by appropriate location of reaction wood. When the stem is cut to remove apical control, the branches start forming reaction wood to bend them upwards, out of their preferred position, with neither mechanical nor gravitational stimulus. A possible explanation is that apical control determines the normal position of branches. When apical control is removed, the preferred position changes and the branch forms reaction wood to bend into the new position.

\section{Effects of shading}

Shading of leaves on an axis, either from competing trees or from upper branches on the same tree, reduces photosynthesis and eventually reduces leaf production and growth. As growth of the branch slows, photosynthesis and hormone production continue to slow. Many trees have small shoots that can continue to grow less than a centimeter each year, but if they are too shaded, they ultimately die. As a result, the lower and internal portions of tree crowns are free of leaf bearing axes unless the foliage on the outer portion is sparse enough to let light through. In the forest, branches whose tips do not reach the top of the canopy soon die and the trunk is left free of branches, but specimen trees in the open may retain lower branches.

In excurrent trees, like many conifers, with a dominant central stem and major branches at wide angles to the stem, upper branches shade lower branches. As a result, there is a regular sequence of branches from the top to the bottom of the crown, each progressively more shaded. If the branch tip can grow out horizontally enough to expose leaves to light, the branch can survive, but in . older branches the costs of growing horizontally are large and branch productivity small. The branches do not thicken much as they grow out and as a result tend to sag down under their own weight. Eventually, the Lowermost branches die. 
In decurrent trees, there is no single dominant stem and branches tend to curve upward so their tips are a the canopy surface. Good examples are mature Quercus spp. with wide spreading crowns. Lower branches that do not bend up still are shaded out, particularly in the forest, but the other major branches thicken so that there is no semblance of a central stem in the upper crown.

\section{Allocation mechanisms}

As branches grow, the photosynthate produced by their leaves is allocated to their own growth and to the growth of the rest of the tree. Axes with the most leaves thicken most, thus maintaining both adequate water transport capacity to the leaves and mechanical strength to support the leaves $(9,13,19)$. The ratio of sapwood area proximal to leaf surface area stays fairly constant. The constancy of the ratio reflects a feedback mechanism between the amount of leaves and the rate of wood formation producing new tracheids and vessels for water transport to replace the old ones that have been embolized and are no longer functional (19).

Axes with leaves produce the photosynthate and hormones regulating wood formation. Those axes with the most leaves produce the most materials and also transpire the most water. The hormones stimulate cambial activity. The basipetal transport of auxin restricts most of this stimulation to the sequence of axes leading from the leaves to the stem and the root system. This same sequence of axes serves as the direct channel for water transport in the reverse direction. Therefore, axes thicken in proportion to the amount of leaves they serve. They produce more wood and more transport capacity, thus maintaining the ratio of leaves to sapwood.

The feedback between leaves and wood production seems obvious, but how is the wood distributed along a series of axes many meters long and far from the leaves? Axes thicken in such a way that cells at the cambium undergo the same strains in bending all along the axis. The so-called "constant strain hypothesis" (17) suggests that wood is added preferentially to those areas along the axis where bending strains are the greatest. In addition, the axes with the most leaves and the largest bending moment would thicken the most because they would bend the most in the wind and thus develop the greatest strains in bending. There are still many unanswered questions about how a strain feedback system could interact with the feedback between leaves and wood production to ensure the proper distribution of strength and transport characteristics within the branching system of the tree.

\section{Literature Cited}

1. Blake, T. J., R.P. Pharis, and D.M. Reid. 1980. Ethylene, gibberellin, auxin and apical control of branch angle in Cupressus arizonica. Planta 148:64-68.

2. Brown, C. L., R.G. McAlpine, and P.P. Kormanik. 1967. Apical dominance and form in woody plants: a reappraisal. Amer. J. Bet. 54:153-162.

3. Brunig, E.F. 1976. Tree forms in relation to environmental conditions: an ecological viewpoint, p. 139-156. In: M.G.R. Cannell and F.T. Last (eds.). Tree physiology and yield improvement. Academic, New York.

4. Champagnat, P. 1978. Formation of the trunk in woody plants, p 401-422. In: P.B. Tomlinson and M.H. Zimmerman (eds.). Tropical trees as living systems. Cambridge Univ. Press, Cambridge.

5. Hallé, F., R.A.A. Oldeman, and P.B. Tomlinson. 1978. Tropical trees and forests. Springer-Verlag, New York.

6. Jensen, E.C. and J. N. Long. 1983. Crown structure of a co-dominant Douglas-fir. Can. J. For. Res. 13:264-269.

7. Kramer, P.J. and T.T. Kozlowski. 1979. Physiology of woody plants Academic, New York.

8. Little, C.H.A. 1970. Apical dominance in long shoots of white pine (Pinus strobus L.). Can. J. Bot. 48:239-253.

9. Long, J. N., F.W. Smith, and D.R.M. Scott. 1981. The role of Douglas-fir stem sapwood and heartwood in the mechanical and physiological support of crowns and the development of stem form. Can. J. For. Res. 11:459-464.

10. Sinnot, E.W. 1952. Reaction wood and the regulation of tree form Amer. J. Bet. 39:69-78.

11. Smith, A.R. 1984. Plants, fractals and formal language, Computer Grahics 18(3):1-10.

12. Ward, H.M. 1909. Trees. Vol V. Form and habit. Cambridge Univ. Press, Cambridge.

13. Waring, R. H., P.E. Schroeder, and R. Oren. 1982. Application of the pipe model theory to predict canopy leaf cover. Can. J. For. Res. 12:556-560.

14. Wilson, B.F. 1981. Apical control of diameter growth in white pine branches. For. Sci. 27:95-101.

15. Wilson, B.F. 1984. The growing tree. Rev. ed. Univ. of Massachusetts Press, Amherst.

16. Wilson, B.F. 1986. Apical control of compression wood action in white pine branches. Wood Sci. Technol. 20:111-117.

17. Wilson, B.F. and R.R. Archer. 1979. Tree design: some biological solutions to mechanical problems. Bioscience 9:293-298.

18. Woodman, J.N. 1971. Variation of net photosynthesis within the crown of a large, forest-grown conifer. Photosynthetica 5:50-54.

19. Zimmerman, M.H. 1983. Xylem structure and the ascent of sap. Springer-Verlag, Berlin.

20. Zimmerman, M.H. and C. L. Brown. 1971. Trees: structure and function. Springer-Verlag, New York.

\title{
Tree Branch Attachment to Trunks and Branch Pruning
}

\author{
Alex L. Shigo \\ U.S. Forest Service, Northeastern Forest Experiment Station, U.S. Department of Agriculture, P. O. Box 640, \\ Durham, NH 03824
}

The vascular cambium and the growth ring it produces are continuous from trunk to branch, but the cells formed by the cambium in the upper junction of branch and trunk deviate from the normal orientation of trunk to branch by angles approaching $90^{\circ}$. Branch tissues begin to develop before trunk tissues early in the growing season. Maturation of branch tissues proceeds basipetally. The branch

The full text of this paper appeared in Can. J. Bet. 63:1391-1401; 1985. I thank Kenneth Dudzik for the photographs and especially the montage made up of 56 photographs in Fig. 8; H. Sharon Ossenbruggen and Tess Feltes for artwork; Tom van der Zwet for samples of pear infected with Erwinia amylovora; and Kevin Smith and Philip Larson for valuable discussions on the subject. xylem is oriented downward at the branch base and encircles it to form a collar. The collar tissues meet on the trunk below the branch. This branch collar is enveloped later in the growing season by the basipetal development of trunk xylem. Xylem in the trunk collar encircles tbe branch junction. The branch is structurally attached to the trunk by a series of trunk collars that envelop the branch collars every growing season. When the trunk collar is injured or removed by branch pruning, the trunk xylem above and below the cut is rapidly and extensively infected, and decay develops. When pruning cuts do not injure or remove the trunk collar, no infections develop in the trunk xylem.

Dye movement and patterns of spread of bacterial and fungal pathogens also suggest that there is no local direct conduction between trunk xylem above a branch and within a branch. 